From the clinic

\title{
Surgical stabilization of spondylolisthesis in a wrestler
}

\author{
Gerardo L. Garcés MD PhD and José L. Rasines MD \\ Instituto Canario de Cirugía Ortopédica y Traumatología (Clínica San Roque), Clinical Sciences Department, \\ University of Las Palmas de Gran Canaria, Spain
}

\begin{abstract}
Sporting activity in wrestlers operated on for spondylolisthesis is not well documented in the literature. We present the case of a wrestler with a grade I L5-S1 spondylolisthesis who was L4-S1 arthrodesed due to pain not relieved by conservative methods. One year after surgery he had returned to full wrestling activity, including competitions. Two years later, he continues to wrestle at the same level of competition.
\end{abstract}

Keywords: spondylolisthesis, wrestling, surgical treatment

Spondylolysis and spondylolisthesis are the most frequent causes of chronic spine injuries in sport. Their prevalence and incidence are related to the type of sport, being $20-33 \%$ in wrestling ${ }^{1,2,3}$. The initial treatment of low grade spondylolisthesis is conservative and its occurrence does not impede the practice of sport. Only those cases not responding to conservative treatment should be surgically treated. However, it is not clear in the literature if patients operated on for this problem can return to their previous level of sporting activity.

We report the case of a player of Canarian wrestling, suffering from painful low grade spondylolisthesis. Canarian wrestling is an autoctonous modality of wrestling characterized by the great strength that is needed by the paravertebral muscles, both in flexion and hyperextension of the lumbar spine (Figure 1). In competition, there is no separation of wrestlers by weight, and the effort required by some competitors can be very considerable.

\section{Case report}

A 24-year-old male professional player of Canarian wrestling came to our Institution complaining of low back pain of several months duration, radiating down to the left knee, that increased after exercising and was relieved by rest. Physical examination showed a lumbar muscle contracture and pain both in flexion and extension of the lumbar spine. There was no limitation to range of movement and neurological

Address for correspondence: Dr Gerardo L. Garcés MD PhD, D. Pío Coronado 164, 35012 Las Palmas, Spain

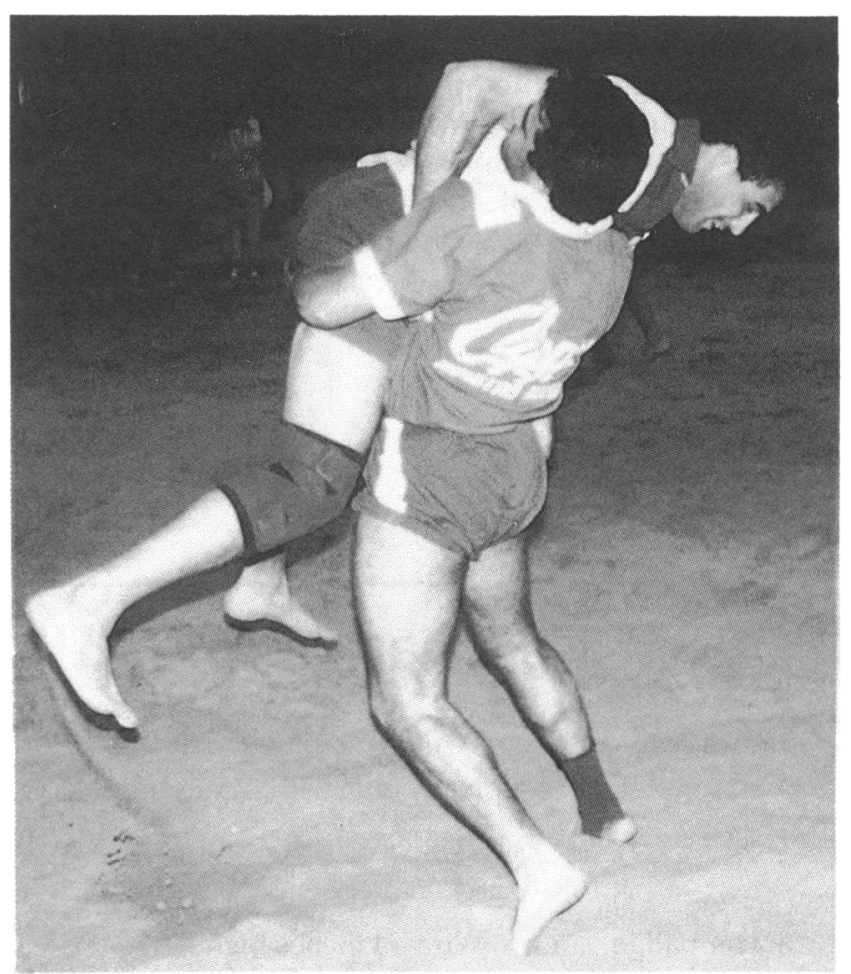

Figure 1.

examination was completely normal. Radiographs showed a grade I L5-S1 spondylolisthesis; computerized tomography and magnetic resonance imaging showed some slight disc protrusions at L4-L5 and L5-S1 levels. Bone scintigraphy was completely unspecific. With the diagnosis of stable low grade lumbosacral spondylolisthesis, the patient was advised to restrict his sporting activities and avoid lumbar hyperextension. A special programme of physiotherapy was supplemented with non-steroidal anti-inflammatory drugs and electrotherapy.

In spite of these measures, the pain continued. An L4-S1 posterior arthrodesis fixed with bars and intrapedicle screws was carried out without reducing the sliding (in situ arthrodesis). Postoperatively the patient wore an antilordosant brace for 4 months and 
followed a special programme of physiotherapy. Seven months after the operation he recommenced wrestling training. One year postoperatively, he re-entered competition level. Two years after having restarted, he continues to wrestle at the same level and is completely asymptomatic.

\section{Discussion}

Low grade lumbar isthmic spondylolisthesis is initially treated conservatively. Several methods including physiotherapy, bracing and activity modification have been shown to be successful. When conservative measures fail to improve symptoms, surgical treatment is recommended. The current trend is to restore normal anatomy and to retain arch of movement at the involved level. To afford this, two groups of techniques are currently used: direct repair of the defect by screw fixation ${ }^{4,5,6}$ and tension-band wiring and bone grafting $7,8,9,10$. In spite of this principle, some authors still prefer to make an in situ arthrodesis of the involved vertebrae ${ }^{11,12,13,14}$.

Most conservatively treated athletes with low grade spondylolisthesis can return to full sporting activities. Only those cases who remain symptomatic when practising sport are recommended to be operated on. There is very little published experience about the sporting outcome of patients operated on for this problem $6,7,10$.

We operated on our patient after the conservative programme failed to relieve his symptoms. We chose a bisegmental arthrodesis rather than a direct repair of the defect because of the intervertebral disc damage shown by the magnetic resonance imaging. Although disc herniation is recognized as a rare condition associated with spondylolisthesis ${ }^{15}$, disc degeneration in retired wrestlers is clearly higher than in the normal population ${ }^{16}$. Lumbar spine stress developed during wrestling is also considerably higher, which has been claimed as one of the main causes of the high incidence of spondylolysis and spondylolisthesis in this sport. In this sense, Canarian wrestling does not differ from the rest of wrestling modalities.

We have treated several other wrestlers for spondylolysis and spondylolisthesis who have not needed surgical treatment and have continued wrestling. Since we do not know of any other reports about returning to wrestling after surgical treatment for spondylolisthesis, we cannot advise this as a rule. However, the results observed with this patient let us assume that wrestlers operated on for this problem do not necessarily have to retire.

\section{References}

1 Jackson D. Low back pain in young athletes: evaluation of stress reaction and discogenic problems. Am J Sports Med 1979; 7: 364-66.

2 Rossi F, Dragoni S. Lumbar spondylolysis: occurrence in competitive athletes. Updated achievements in a series of 390 cases. I Sports Med Phys Fitness 1990; 30: 450-52.

3 Roy-Camille R. Quoted by Taillan R, Commadre F, Ziegler G Euller Y, Ziegler L. Spondylolyse-Spondylolisthesis et sports. In: Rodineau J, Simon L. Microtraumatologie du Sport. Paris France: Ed Masson, 1987.

4 Ohmori K, Suzuki K, Ishida Y. Translamino-pedicular screw fixation with bone grafting for symptomatic isthmic lumbar spondylolysis. Neurosurg 1992; 30: 379-84

5 Bonnici AV, Koka SR, Richards DJ. Results of Buck screw fusion in grade I spondylolisthesis. J $R$ Soc Med 1991; 84: 270-73.

6 Hardcastle P. Repair of spondylolysis in young fast bowlers. J Bone Joint Surg 1993; 75: 398-402.

7 Roca J, Moretta D, Fuster S, Roca A. Direct repair of spondylolysis. Clin Orthop 1989; 246: 86-91.

8 Hambly M, Lee C, Gutteling E, Zimmerman M, Langrana N, Pyun $Y$. Tension band wiring bone grafting for spondylolysis and spondylolisthesis. A clinical and biomechanical study. Spine 1989; 14: 455-60.

9 Johnson GV, Thompson AG. The Scott wiring technique for direct repair of lumbar spondylolysis. J Bone Joint Surg 1992; 74: $426-30$.

10 Salib RM, Pettine KA. Modified repair of a defect in spondylolysis or minimal spondylolisthesis by pedicle screw, segmental wire fixation, and bone grafting. Spine 1993; 18: 440-43.

11 Roy-Camille R, Benazet JP, Desauge JP, Kuntz F. Lumbosacral fusion with pedicular screw plating instrumentation. A 10-year follow-up. Acta Orthop Scand Suppl 1993; 251: 100-4.

12 Boos N, Marchesi D, Aebi M. Treatment of spondylolysis and spondylolisthesis with Cotrel-Dubousset instrumentation: a preliminary report. J Spinal Disord 1991; 4: 472-79.

13 Boos N, Marchesi D, Heitz R, Aebi M. Surgical treatment of spondylolisthesis with mild displacement by pedicular fixation and posterolateral fusion in adults. Rev Chir Orthop Reparatrice Appar Mot 1992; 78: 228-35.

14 Dickman CA, Fessler RG, MacMillan M, Haid RW. Transpedicular screw-rod fixation of the lumbar spine: operative technique and outcome in 104 cases. J Neurosurg 1992; 77: 860-70.

15 Poussa M, Tallroth K. Disc herniation in lumbar spondylolisthesis. Report of 3 symptomatic cases. Acta Orthop Scand 1993; 64: 13-16.

16 Granhed $\mathrm{H}$, Morelli B. Low back pain among retired wrestlers and heavyweight lifters. Am J Sports Med 1988; 16: 530-33. 